\title{
Cytokinetic Abscission Regulation in Neural Stem Cells and Tissue Development
}

\author{
Katrina C. McNeely ${ }^{1}$ (D) $\cdot$ Noelle D. Dwyer ${ }^{1}$ (D) \\ Accepted: 30 June 2021 / Published online: 11 August 2021 \\ (C) The Author(s) 2021
}

\begin{abstract}
Purpose of Review How stem cells balance proliferation with differentiation, giving rise to specific daughter cells during development to build an embryo or tissue, remains an open question. Here, we discuss recent evidence that cytokinetic abscission regulation in stem cells, particularly neural stem cells (NSCs), is part of the answer. Abscission is a multi-step process mediated by the midbody, a microtubule-based structure formed in the intercellular bridge between daughter cells after mitosis.

Recent Findings Human mutations and mouse knockouts in abscission genes reveal that subtle disruptions of NSC abscission can cause brain malformations. Experiments in several epithelial systems have shown that midbodies serve as scaffolds for apical junction proteins and are positioned near apical membrane fate determinants. Abscission timing is tightly controlled and developmentally regulated in stem cells, with delayed abscission in early embryos and faster abscission later. Midbody remnants (MBRs) contain over 400 proteins and may influence polarity, fate, and ciliogenesis.

Summary As NSCs and other stem cells build tissues, they tightly regulate three aspects of abscission: midbody positioning, duration, and MBR handling. Midbody positioning and remnants establish or maintain cell polarity. MBRs are deposited on the apical membranes of epithelia, can be released or internalized by surrounding cells, and may sequester fate determinants or transfer information between cells. Work in cell lines and simpler systems has shown multiple roles for abscission regulation influencing stem cell polarity, potency, and daughter fates during development. Elucidating how the abscission process influences cell fate and tissue growth is important for our continued understanding of brain development and stem cell biology.
\end{abstract}

Keywords Cytokinesis $\cdot$ Abscission $\cdot$ Neural stem cells $\cdot$ Cell fate $\cdot$ Microcephaly $\cdot$ Midbody

\section{Introduction}

Proper development of the mammalian brain requires a series of coordinated cell divisions to produce tremendous numbers of neurons and glia at the correct times. Embryonic neural stem cells (NSCs) reside in a polarized epithelium and have a highly polarized structure that extends from the basal lamina to the ventricular surface. The apical membranes (apical endfeet) are joined by adhesive junctions and make up the

This article is part of the Topical Collection on Stem Cell Switches and Regulators

Noelle D. Dwyer

ndwyer@virginia.edu

Katrina C. McNeely

ko4ek@virginia.edu

1 Department of Cell Biology, University of Virginia School of Medicine, PO Box 800732, Charlottesville, VA, USA lateral ventricle walls. The NSC nuclei migrate within the cell during the cell cycle: basally before S-phase and apically to the ventricular surface for mitosis (Figure 1). Early in development ( embryonic day (E)8-E11 in mouse), NSCs expand the pool of stem cells through proliferative symmetric division. This increases the area of the neuroepithelial sheet. Later ( $\sim$ E12), NSCs begin to gradually switch to asymmetric divisions, to start making neurons. Neurons are post-mitotic cells that do not divide again. They migrate away from the ventricle to form the cortical plate (cp, neuronal layer). Thus, neurogenesis increases the thickness of the brain [1]. How NSCs regulate these modes of division to create the correct number and types of daughter cells and make a brain of the correct size and structure is an intense area of study. This review will discuss recent literature suggesting that regulation of cytokinetic abscission plays a role in this process.

NSCs undergo a polarized form of cytokinesis that may be important for maintaining their stemness, as well as their polarity and epithelium integrity. These tall thin cells must split 
Fig. 1 Embryonic cortical NSC modes of division and daughter cell types. Schematic of cross section of embryonic mouse cerebral cortex shows a neural stem cell (NSC) undergoing mitosis $(\mathrm{M})$ and polarized cytokinesis. The midbody (MB) forms at the apical membrane and mediates abscission. See text for more details. cp, cortical plate; iz, intermediate zone; svz, subventricular zone; vz, ventricular zone

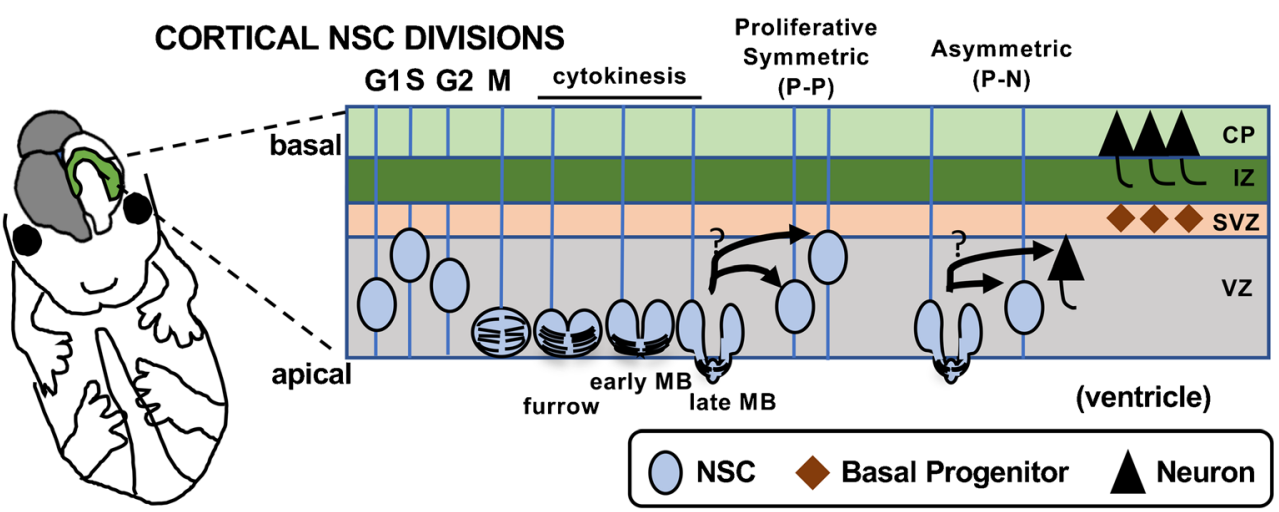

their organelles, cytoplasm, membrane, and apical cell junctions into two daughter cells of equal or unequal fates. Cytokinesis consists of two distinct steps: cleavage furrowing and abscission. The cleavage furrow ingresses from basal to apical, forming an intercellular bridge at the apical membrane (Figure 1). The intercellular bridge contains the compacted antiparallel microtubules of the central spindle, which form the midbody (MB). The midbody serves as a platform that mediates the process of abscission, severing the intercellular bridge.

Much of our knowledge about the mechanisms of abscission comes from studies in cell lines or single cell systems. Abscission takes much longer than cleavage furrowing, completing in G1 phase of the next cell cycle in HeLa cells [2]. The midbody is comprised of over 400 proteins [3••, 4] that assemble within two major subdomains: a central bulge with an electron-dense core, sometimes called the Flemming body, and flanks on each side (Figure 2A, B) [5, 6]. As the midbody matures, a constriction site (cs) will form on each flank, with local thinning where severing will occur. Midbody severing involves both local disassembly of the cytoskeleton (microtubules, actin, and septins) and scission of the plasma membrane (for review, see [7, 8]). Microtubule disassembly happens concurrently with membrane scission, both thought to be mediated by endosomal sorting complex required for transport (ESCRT) machinery [9, 10]. These sequential steps in the process of abscission can be visualized by observing changes in the midbody microtubule organization (Figure 2C). After abscission, the central bulge remains intact and is known as the midbody remnant (MBR). In cells where both midbody flanks are severed, the MBR is released extracellularly. It may remain on the cell surface, or be internalized by a daughter cell or other nearby cell. Several roles for MBRs have been proposed to transmit signals to neighboring cells through surface binding or internalization [11-15] including influencing stemness or differentiation $[16,17]$

Work from the past decade provides increasing evidence that abscission regulation plays roles in many developmental processes, including cell fate determination, polarization, and tissue morphogenesis. This review will focus on the importance of abscission regulation in neural stem cells for proper mammalian brain development. Strong evidence is provided by mutations in abscission genes in both mice and humans that cause brain malformations. Analyses of abscission defects in these mouse mutants, as well as data from simpler systems, suggest that three particular aspects of abscission must be tightly regulated by NSCs as they build the brain: midbody positioning, abscission timing, and midbody remnant handling. In vivo studies of the mechanisms and roles of abscission in stem cells and tissue development have only just begun, and many questions remain.

\section{Mouse and Human Mutations Reveal Dire Consequences of Abscission Dysregulation in Neural Stem Cells}

Brain development is particularly vulnerable to defects in cytokinetic abscission. This is made evident by human and mouse mutations of abscission genes that cause forms of microcephaly: Cep55, Kif20A, Kif20B, Kif14, CitK, and Sept7 [18-35]. With the exception of Sept7, all of these mutations affect brain growth more severely than that of other tissues. Interestingly, two of these genes, Cep55 and Kif20B, are not present in invertebrate genomes, suggesting they may have evolved to help build bigger more complex nervous systems. While there are other cytokinesis genes expressed in NSCs, we focus on these six because they have relatively specific roles in abscission as defined in cell line studies, and the mouse knockouts have documented defects in cortical development (see Table 1).

The proteins encoded by these genes all localize to the midbody and play different roles in regulating abscission. These roles were first defined by studies in mammalian cell lines. Two related kinesin motor proteins of the Kinesin- 6 family, Kif20A (also called MKLP2) and Kif20B, localize on the midbody flanks, but with slightly different spatiotemporal patterns $[28,36]$. Kif20B appears to be important for tight bundling of midbody microtubules, while Kif20A is required to localize Aurora B kinase to the midbody, and both 


\section{A MIDBODY STRUCTURE}
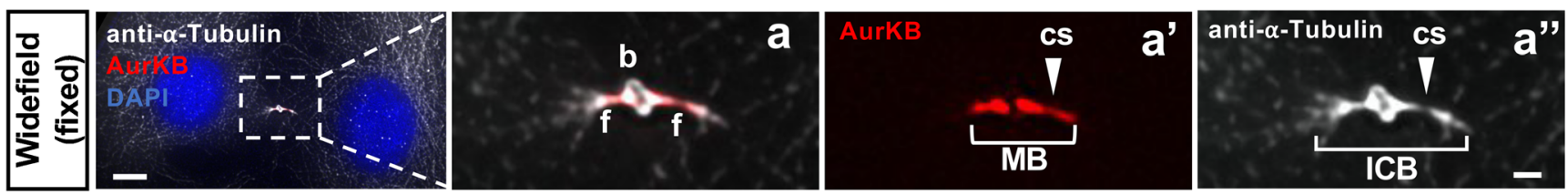

B
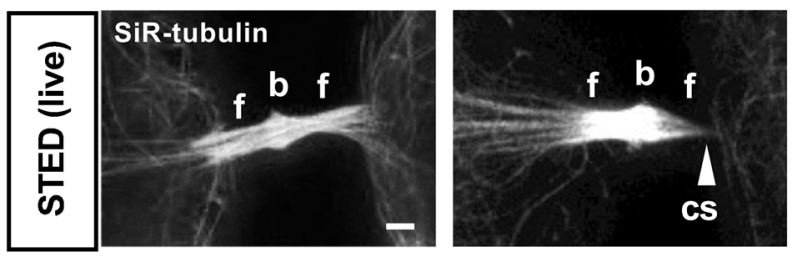

\section{ABSCISSION PROCESS}

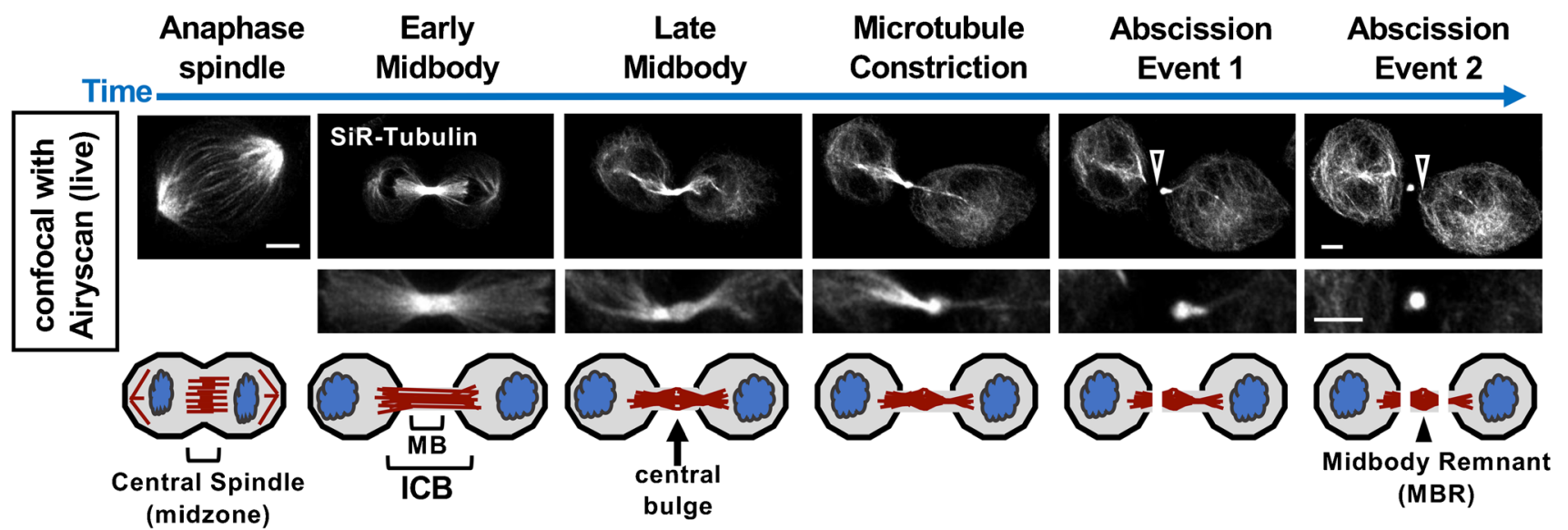

Fig. 2 Midbody subdomains and abscission process. (A) Widefield image of a mouse embryonic fibroblast at a late stage of abscission, fixed and immunostained for alpha-tubulin (white) and Aurora B kinase (AurKB, red, MB flanks). ICB, intercellular bridge; b, bulge; f, flank; cs, constriction site. (B) The microtubule organization of midbodies is revealed by labeling live HeLa cells with SiR-Tubulin, and stimulated emission depletion (STED) microscopy. (C) Steps in the abscission process visualized in live cells with SiR-tubulin. The midbody is

formed by the compaction of central spindle microtubules, then matures, gradually becoming thinner with a central bulge and constriction sites. Microtubules are disassembled to sever each flank (arrowhead), completing the separation of daughter cells and releasing the MBR extracellularly. HeLa cells were imaged by time-lapse confocal microscopy with Airyscan. Scale bars: $1 \mu \mathrm{m}$ in Aa-Aa",B; $5 \mu \mathrm{m}$ in A,C. See [36] for methods

appear to regulate abscission timing [36-38]. Kif20A has been shown to interact with a midbody flank protein, Septin 7 (Sept7) [23]. Septins are GTP-binding proteins that form filaments at the cell cortex or with other cytoskeletal proteins. Sept7 localizes to the central spindle during furrowing and to the central bulge of the midbody during abscission, and is believed to be important for both the maintenance of the furrow and microtubule disassembly at abscission sites [35, 39, 40]. Kif14 (of the Kinesin-3 family) is required to localize Citron Kinase (CitK) to the central spindle and central bulge of the midbody [41]. CitK regulates abscission timing and helps to maintain midbody stability [42]. Cep55 is a coiledcoil protein that forms a disc at the middle of the central bulge, and ensures efficient recruitment of TSG101 and Alix, which then recruit the ESCRT-III components that mediate scission of the midbody (for review, see [43]).

While studying cytokinesis gene functions in cell lines helps to understand how they cause disease, studying the in vivo phenotypes of humans and mice carrying mutations is necessary to elucidate the mechanisms and roles of abscission regulation in stem cells and development. Cell line studies in two-dimensional culture cannot model certain aspects of stem cell biology such as three-dimensional structures, or giving rise to different daughter cell types at different times in development. Perhaps not surprisingly, all six of the abscission genes we are discussing have been associated with human cancers. Thus far, three of them, CEP55, KIF14, and CITK, have been associated with specific human 
Table 1 Abscission gene mutations cause microcephaly and other phenotypes in mouse and human. Abbreviations: $M B$ midbody, $M B R$ midbody remnant, $C S$ constriction site, AurKB Aurora kinase B, mcph microcephaly, $M C D$ malformations of cortical development, $I D / D D$ intellectual disability/developmental delay

\begin{tabular}{|c|c|c|c|c|c|c|}
\hline Gene & Cep55 & Kif20A (MKLP2) & Kif20B & Kif14 & Citron Kinase (CitK) & Sept7 \\
\hline $\begin{array}{r}\text { Abscission } \\
\text { function }\end{array}$ & Recruit ESCRTs & $\begin{array}{l}\text { Localize AurKB } \\
\text { to MB }\end{array}$ & MT bundling & $\begin{array}{l}\text { Localize CitK to } \\
\text { MB }\end{array}$ & $\begin{array}{l}\text { Maintain MB stability, } \\
\text { Localize Kif14 }\end{array}$ & $\begin{array}{l}\text { Maintain } \\
\text { furrow stability }\end{array}$ \\
\hline $\begin{array}{l}\text { Midbody } \\
\text { localization }\end{array}$ & $\begin{array}{l}\text { Central bulge, } \\
\text { MBR }\end{array}$ & Flanks & $\begin{array}{l}\text { Early MB: Flanks } \\
\text { Late MB: CS }\end{array}$ & $\begin{array}{l}\text { Central bulge, } \\
\text { MBR }\end{array}$ & Central bulge, MBR & Central bulge, MBR? \\
\hline $\begin{array}{l}\text { NSC } \\
\text { midbody } \\
\text { Phenotype }\end{array}$ & $\begin{array}{l}\text { Shorter, } \\
\text { not misaligned }\end{array}$ & Unknown & $\begin{array}{l}\text { Wider, } \\
\text { misaligned }\end{array}$ & Unknown & Unknown & Unknown \\
\hline $\begin{array}{l}\text { Cortical } \\
\text { thickness }\end{array}$ & $\downarrow$ & $\downarrow \downarrow$ & $\downarrow \downarrow$ & $\downarrow$ & $\downarrow$ & $\downarrow \downarrow$ \\
\hline $\begin{array}{l}\text { NSC } \\
\text { abscission } \\
\text { Duration }\end{array}$ & Longer & Unknown & Shorter & Unknown & $\begin{array}{l}\text { Patient-derived NPCs: } \\
\text { longer duration }\end{array}$ & Unknown \\
\hline $\begin{array}{l}\text { Binucleate } \\
\text { cells }\end{array}$ & $\begin{array}{l}\text { Yes } \\
\text { (mouse, human) }\end{array}$ & No & No & Unknown & $\begin{array}{l}\text { Yes } \\
\text { (mouse, rat, human) }\end{array}$ & No \\
\hline $\begin{array}{l}\text { Cell cycle } \\
\text { exit }\end{array}$ & E12.5: $\uparrow$ & $\mathrm{E} 15.5: \uparrow$ & Unknown & Unknown & Unknown & $\mathrm{E} 15.5: \uparrow$ \\
\hline Apoptosis & $\uparrow \uparrow$ & $\uparrow$ & $\uparrow$ & $\uparrow \uparrow$ & $\uparrow \uparrow$ & $\uparrow \uparrow$ \\
\hline $\begin{array}{l}\text { Human } \\
\text { syndromes }\end{array}$ & $\begin{array}{l}\text { mcph, variable } \\
\text { MCD, ID/DD, } \\
\text { abnormal } \\
\text { muscle tone, } \\
\text { digits, kidney }\end{array}$ & Unknown & Unknown & $\begin{array}{l}\text { mcph, variable } \\
\text { MCD, ID/DD, } \\
\text { abnormal digit, } \\
\text { eye, kidney }\end{array}$ & $\begin{array}{l}\text { mcph, variable MCD, } \\
\text { ID/DD, short stature, } \\
\text { abnormal muscle tone, kidney }\end{array}$ & Unknown \\
\hline Refs & $18,20,24,29-31$ & 28 & 21,65 & $25-27,32$ & $22,33-34$ & 23,35 \\
\hline
\end{tabular}

microcephaly syndromes (Table 1). Depending on the specific mutation, lethal or non-lethal syndromes affecting development of the brain and other organs can result. A common feature of patients with non-lethal disease is intellectual and developmental delay (ID/DD). The lethal syndromes often affect development of both the kidney and cerebellum. To probe the roles of these and other cytokinesis genes in brain development, we depend primarily on mouse models.

The gross phenotypes of the mouse mutants in these abscission genes share some features in common (Table 1). Perhaps unexpectedly, the homozygous knockouts, with the exception of Sept 7, are able to develop fairly normally up until birth, but die soon after [19, 21, 24, 25, 28, 29]. Interestingly, Sept 7 can only be studied as a conditional mutant because the null embryos die between E7 and E10 [23, 35]. Two mutants have a noticeably smaller body at birth (Kif20B and Kif20A), while three have almost normal body size when born, but then fail to thrive postnatally (Cep55, Kif14, and CitK). Three of the mutants have flat foreheads (Cep55, CitK, and Kif14), and one has a short snout and small eyes (Kif20B).

Knockout mice of all of these abscission genes have small cerebral cortices (microcephaly). Remarkably, most have preserved layer structure, even though layers are thinner. The exception is the Kif14 mutant, which has superficial layer neurons present in deep layers, suggesting a possible neuron migration defect [25]. Interestingly, all of the flat-headed mutants have ataxia, which could be caused by the observed defects in cerebellum development.

What are the consequences for the daughter cells of abnormal NSC abscissions that account for the deficits in brain growth? Prior work in cell lines in vitro showed that knockdown of abscission genes could cause daughter cells to become binucleate or have persistent intercellular bridges. However, in vivo, binucleation is not necessarily a hallmark of these mouse abscission mutants. Cep55 and CitK mutations do result in binucleate cells in both the mouse and human brains [19, 29], but Kif20A, Kif20B, and Sept7 mutations do not [21, 23, 28]. For KIF14 mutations, there are binucleate cells in human patients [26], but it was not examined in the mice. It is not clear if the discrepancies between in vitro and in vivo results are due to compensation, off-target knockdowns, or differences between 2-D cultures and 3-D tissues. Another differing outcome from gene loss in cell lines versus in vivo is in regard to apoptosis. Immortalized or cancer cell lines do not have normal regulation of apoptosis, although it is sometimes reported after long delays in abscission failure [44, 45]. However, there is elevated apoptosis in the brains of all of these mouse mutants $[19,21,23-25,28,29,46,47]$. This apoptosis was determined to be p53-dependent in Cep55, Kif20B, and CitK mutants. In the Cep55 knockout, p53 
elevation was shown to correlate with binucleation in NSCs [29•]. Importantly, NSCs appear to have a lower threshold for p53 activation than other cell types [29•, 46, 48]. A third consequence of abscission dysregulation that is different in vitro versus in vivo is cell cycle arrest versus cell cycle exit for differentiation. Some cell lines such as RPE1 cells can exhibit cell cycle arrest after failures of cytokinesis, but in vivo, cells that fail cytokinesis can differentiate. During normal embryonic brain development, the daughter cells of NSC divisions that commit to a neuron cell fate exit the cell cycle and terminally differentiate [49]. In Cep55, Kif20A, and Sept7 mutants, there are excess neuron progeny at early ages (premature neurogenesis). Additionally, individual NSC divisions were analyzed in these mouse mutants. All of them have an increase in neurogenic divisions at the cost of proliferative symmetric divisions, meaning that more daughter cells exit the cell cycle to differentiate into neurons [23, 28, 29•]. Unlike apoptosis, the increased neurogenesis is not dependent on p53, at least in the Cep55 knockout [29•]. Together these data suggest that disruption of abscission regulation can cause microcephaly by depleting stem cells, either directly or indirectly, through apoptosis and premature neurogenesis, perhaps sometimes after binucleation.

The amount of binucleation, apoptosis, and premature neurogenesis vary in these different gene knockouts. What are the precise abscission defects in NSCs caused by loss of these abscission genes? In the cases where the knockout studies did not specifically analyze cytokinesis regulation during brain development, the direct roles these proteins play in epithelial NSC abscission are not clear. In the remainder of this review, we will focus on the mouse mutants in Cep55 and Kif20B, for which specific roles in NSC abscission were identified, as well as informative perturbations of abscission in simpler model systems. We will discuss three particular aspects of abscission that these studies have identified as important for stem cell, epithelial, and brain development: midbody position, abscission duration, and MBR disposal.

\section{Midbody Positioning in Cell Division Can Provide Polarity Cues to Daughter Cells}

In many dividing cells, remnants of cytokinetic abscission provide polarity cues for daughter cells. Budding yeasts do not have a midbody, but the site of abscission from the previous division, the bud scar, determines where the next bud will form [50]. In the C. elegans zygote, the midbody remnant from the first cell division is internalized by the posterior daughter cell, moves ventrally, and thereby helps establish dorsal-ventral polarity within the embryo [15]. Newborn neurons in C. elegans and Drosophila appear to use cytokinesis remnants to establish an apical pole where the first neurite grows [51, 52]

\section{Midbody Positioning Is Associated with Apical Membrane and Apical Junctions in Polarized Epithelia}

Accumulating evidence suggests that MB and MBR positioning contributes to apical membrane polarity and lumen formation set-up in early development. When Madin-Darby Canine Kidney (MDCK) cells are grown in 3-D culture, a cyst-like structure will form with an apical membrane facing a fluidfilled lumen. In this system, lumen formation is initiated by the assembly of an "apical membrane initiation site" at the midbody, and maintained by consistent MB positioning at the apical membrane [53, 54]. After abscission, the MBRs remain at the MDCK apical membrane; but, if they are experimentally displaced, ectopic lumen formation occurs [55]. The strongest evidence for midbody positioning inducing apical polarity comes from in vivo experiments in zebrafish. During formation of the Kupffer's vesicle (KV), the MBs are positioned at the center of a cellular rosette and appear to serve as a scaffold for apical polarity components essential for establishing the lumen. Supporting this idea, when abscission completion was experimentally disrupted, lumens were smaller or failed to form [56•].

Additionally, recent work shows that established polarized epithelia coordinate the positioning of abscission and the midbody with apical adhesive junctions in order to maintain polarity. Epithelial cells must ensure that when they undergo mitosis and cytokinesis, both daughter cells inherit apical membrane and cell junctions, while not creating holes in the membrane. To accomplish this, asymmetric cleavage furrowing and positioning of the MB appears to be essential [57, 58]. In Xenopus gastrula embryos, after asymmetric cleavage furrowing completes and the midbody is established, new tri-cellular tight junctions are formed basal to and on either end of the MB [59]. In Drosophila sensory organ precursor cell divisions, the new apical junction forms prior to abscission near the midbody [60]. In Drosophila ovary follicular epithelium, when apical junction proteins were experimentally mislocalized on baso-lateral membrane, midbodies formed more basally and epithelial invaginations were observed [61].

The relationship between apical junctions and midbody positioning has not been directly tested in the developing mammalian brain. In the mammalian neuroepithelium, the apical membrane is the site of polarity cues, cell-cell junctions, and cilia formation. As NSCs go through the cell cycle and divide, they must maintain their apical membrane attachment and re-grow their cilia after each mitosis. In the developing mouse brain, we and others have shown that midbodies align parallel to the apical membrane [21, 62] (Figure 3A, B). When abscission of cortical NSCs occurs and the apical endfoot is split between the two daughter cells, a new adhesive junction is built between the daughter cells, basal to the midbody (Figure 3B, C). The apical junctions appear to surround the 
two flanks of the NSC midbody (Figure 3C). The midbody may interact with nearby candidate fate determinants like apical par complex, Notch/Numb, and centrosomes [59, 62-64]. Interestingly, in one of the abscission mutants, Kif20B, some midbodies are not aligned to the apical membrane [21]. The precise cause of this defect is unclear but could result from a defect in linking the midbody to the apical adhesive junctions, or from premature abscission [65••] before the new apical junctions have fully formed. Following abscission, the midbody remnants remain at the apical membrane or are released into the ventricle $[62,65]$. The placement of both the MB and MBR of NSCs highlights how the spatial localization of abscission may be necessary for downstream cell processes.
How the mammalian NSC MB forms in the apical membrane and interacts with cell junctions, and how this is remodeled during abscission is not well understood. To date, none of the mouse abscission mutants has reported apical junction defects, but this has not been addressed directly.

\section{Abscission Duration May Regulate Stemness Versus Differentiation}

A major question in developmental and stem cell biology is how do stem cells maintain their potency early in development, but also give rise to daughter cells that differentiate

A

B

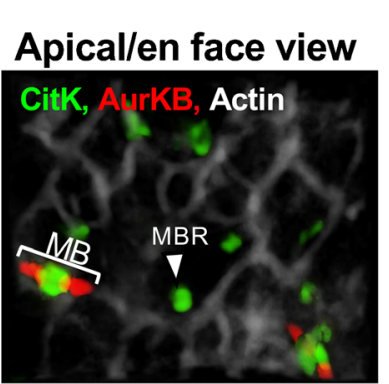

Schematic rotated view

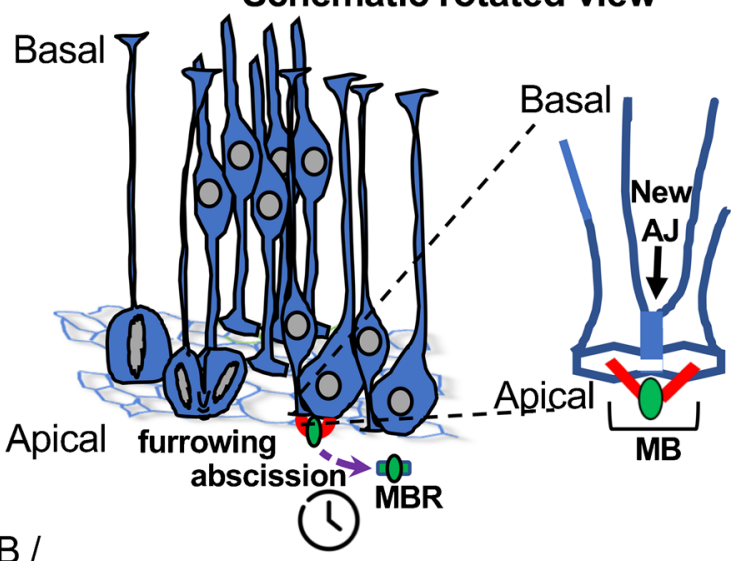

C

Late MB /

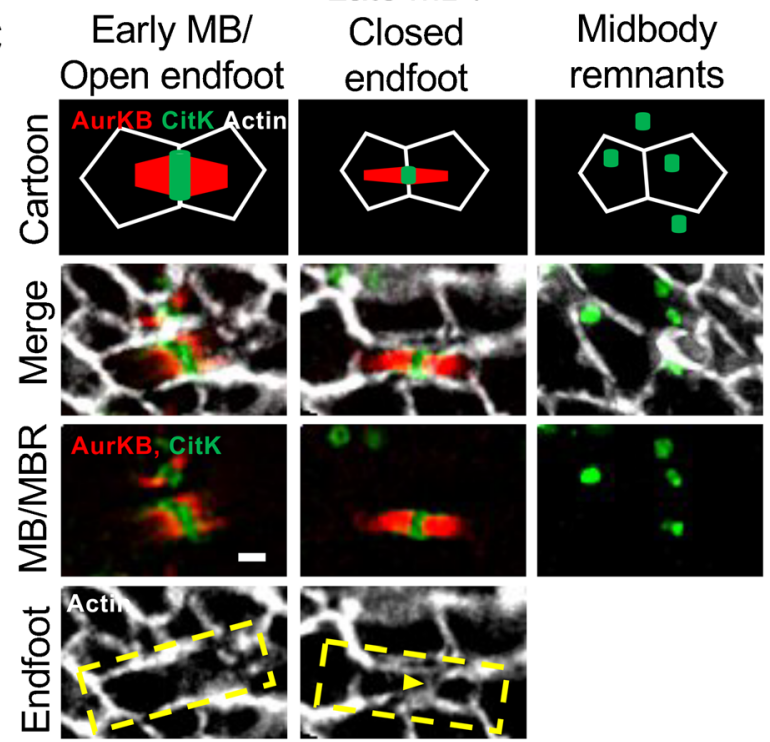

Midbody mnants

D

Possible Roles of MBRs

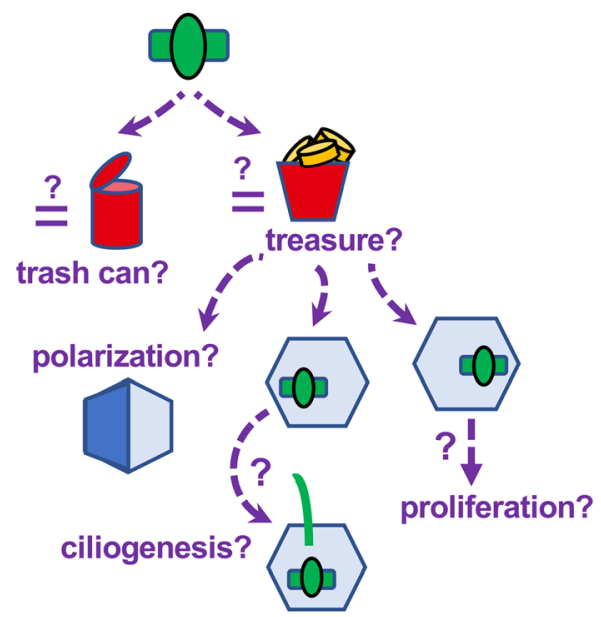

Fig. 3 NSC cytokinetic abscission is coordinated with apical membrane segregation and signaling events. (A) En face view of E11 apical membrane where NSC midbodies (MB) form and midbody remnants (MBRs) are deposited. Cortical slab is labeled with phalloidin (actin, apical junctions, AJ), AurKB (MB flanks), and citron kinase, CitK (central bulge and MBRs). (B) Schematic of NSC cytokinesis at the apical membrane. Zoomed view of a pair of daughter cells connected by a midbody and newly forming AJ. (C) MB maturation coordinates with apical endfoot cleavage and new AJ formation. Early midbodies are wider and surrounded by the "open" NSC endfoot. Late midbody is thinner and the endfoot is "closed," split in two by a new junction (yellow arrowhead) forming between the daughter cells, basal to the MB. MBRs are released at the apical membrane after abscission of both midbody flanks. Scale bar $1 \mu \mathrm{m}$. (D) Schematic of proposed roles of MBRs. The MBR could function as a "trash can" to remove unwanted proteins from the newborn daughter cells, or it could be a "treasure chest" for inducing polarization or promoting ciliogenesis or proliferation. See [65••] for methods. 
and adopt different fates? Fate specification of daughter cells occurs in the same timeframe as abscission in many systems. In some types of stem cells, daughter cells choose their fate during a "commitment window" in G1 phase, in which they may be receptive to extrinsic signals; G1 phase is also when abscission happens $[2,66]$. In Drosophila sensory organ development, binary fate decisions between sister cells are made through Notch signaling at their new cell junction while abscission is proceeding [60]. When a neural stem cell divides, each daughter cell can remain stem-like (self-renew), become an intermediate progenitor, or terminally differentiate into a neuron. In mammalian embryonic cortex, there is a time window of a few hours after mitosis when this cell fate decision is plastic [67]. Since abscission occurs in this time window, in close proximity to fate-signals at the apical membrane, it is plausible that abscission duration could influence the reception of these signals.

As new studies of abscission in different stem cell types in vitro and in vivo are published, a common feature is emerging that early development and stemness are associated with longer duration of abscission than later stages of development. Table 2 shows the duration of abscission, the time between midbody formation and midbody severing, measured in different cell types. In a cultured cancer cell line (HeLa), abscission takes about an hour, but it can be delayed if the cell is under certain kinds of stress [68]. By contrast, a mouse embryonic stem cell line shows developmental regulation of abscission duration. Naïve pluripotent cells took an average of $8 \mathrm{~h}$ to complete abscission, but those exiting from naïve pluripotency took only about half the time to abscise [69••]. Further, delaying abscission by knocking down Alix or Cep55 resulted in an increase in colony formation, suggesting that increased abscission duration helps stem cells retain potency [69••]. In vivo studies provide more evidence. In Drosophila germline stem cell divisions, abscission timing is tightly controlled, and blocking abscission results in mixed daughter fates [70]. In the earliest mouse embryos (4-8-cell stage), the cells are connected by intercellular bridges for extended periods of time $(\sim 9 \mathrm{~h})$ [71]. Similarly, in zebrafish early embryos, for the first five cell cycles, abscission does not occur and the cells remain connected by intercellular bridges. In the 7 th cell cycle, abscission starts to occur with a duration of 40 min, but this decreases to $20 \mathrm{~min}$ by cell cycle 13 [72]. Taken together, these findings from early embryos suggest that delaying stem cell abscission may help maintain their potency or coordinate lineages.

\section{Regulation of Abscission Duration May Be Important for Mammalian Brain Development}

Since data from other systems suggest that early high-potency stem cells have longer abscission duration than later less potent stem cells, we wondered whether abscission duration changes in the NSCs of the developing mammalian brain as development proceeds. Between E11 and E13, NSCs in the developing cortex change their mode of division and the types of daughter cells they can produce. At E11, NSCs usually undergo symmetric proliferative divisions, making two daughter stem cells, whereas at E13, NSCs increase neurogenic divisions, producing some daughter cells that stop dividing to differentiate into neurons. Interestingly, in intact explants of the developing cortex, we found that the average duration of abscission decreased between E11 and E13 [65••]. This developmental regulation is consistent with the idea that the timing of abscission is important for stem cell potency and daughter cell fates.

To test this idea further, we studied two mouse mutants in genes that regulate abscission duration, Kif20B and Cep55. We found that NSC daughter cell fates and brain growth were dramatically disrupted in both mutants. Kif20B is a kinesin-6 family member that localizes to the midbody flanks and constriction sites. When KIF20B is knocked down in a human cancer cell line (HeLa), abscission duration is dysregulated, but still completed [36]. In the brains of mutant mice lacking Kif20B, NSC abscission in the embryonic cortex is faster than in control brains at both E11 and E13. In fact, abscission duration in the mutant mice is almost identical between the two ages ( $\sim 38 \mathrm{~min})$, losing the developmental regulation seen in wild-type brains [65••]. Although this appears to be a modest disruption of abscission timing at the single cell level, there is a profound effect on brain size. This is primarily due to p53mediated apoptosis in some early NSCs that is associated with abscission [21, 46]. In addition, direct examination of E11 NSC daughter cell fates shows that there is a significant loss of stem cell daughters and concomitant gain in neuron daughters $[65 \bullet \bullet$. Therefore, it is an attractive hypothesis that faster abscission promotes excessive differentiation of daughter cells into neurons in this mutant, depleting the stem cells (and precluding their future progeny).

While Kif20B regulation of abscission duration is subtle, Cep55 loss has a more dramatic effect on abscission. Cep55 localizes to the central bulge of the midbody and recruits ESCRT and ESCRT accessory proteins for abscission completion $[73,74]$. When CEP55 is knocked down in HeLa cells, abscission is significantly delayed, and almost all cells fail to abscise, eventually regressing the intercellular bridge and becoming binucleate [75]. Human CEP55 mutations are associated with a series of human developmental syndromes including stillbirths with hydranencephaly in the most severe cases $[18,20,30]$. Surprisingly, despite the severity of human disease and cell line data, the Cep55 knockout mouse mutant is born in normal Mendelian ratios and survives to weaning [24•, 29•]. In the knockout, NSC abscission is significantly slower than control NSC abscission but not delayed to the same degree as in cell lines [29•]. NSC abscission usually succeeds, but also fails in $\sim 25 \%$ of divisions, producing binucleate stem 
Table 2 Abscission duration varies in cell types and species and may decrease as differentiation proceeds. All times are means except times between 1 st and 2 nd abscissions which are medians. Note that comparisons are approximate since different methods of imaging were used. Abbreviations are as follows: $M T$ microtubules, $M B$ midbody, avg average, $h$ hours, $\min$ minutes

\begin{tabular}{|c|c|c|c|c|c|}
\hline & \multirow[t]{2}{*}{ Cell type } & \multirow[t]{2}{*}{ Measurement } & \multicolumn{2}{|l|}{ Duration } & \multirow[t]{2}{*}{ Refs } \\
\hline & & & Time to 1 st abscission & $\begin{array}{l}\text { Time between 1st and 2nd } \\
\text { abscission }\end{array}$ & \\
\hline \multirow[t]{6}{*}{$\begin{array}{l}\text { Cell lines } \\
\text { in vitro }\end{array}$} & $\mathrm{HeLa}$ & $\begin{array}{l}\text { Furrow ingression to } \\
\text { MT disassembly }\end{array}$ & $49-68 \mathrm{~min}$ & $\begin{array}{l}\text { Median: } \\
7.5-14.5 \min \end{array}$ & $\begin{array}{l}10 \\
36\end{array}$ \\
\hline & $\begin{array}{l}\text { NS5 } \\
\text { (mouse NSC cell line) }\end{array}$ & $\begin{array}{l}\text { Arbitrary point in telophase to } \\
\text { MT disassembly }\end{array}$ & $100 \mathrm{~min}$ & avg 40min & 16 \\
\hline & MDCK (dissociated) & $\begin{array}{l}\text { Anaphase to } \\
\text { MT disassembly }\end{array}$ & $2 \mathrm{~h}$ & avg $20 \mathrm{~min}$ & 80 \\
\hline & & $\begin{array}{l}\text { MB formation to } \\
\text { MT disassembly }\end{array}$ & $90 \mathrm{~min}$ & $?$ & 55 \\
\hline & mouse ES cell line & $\begin{array}{l}\text { MB formation to } \\
\text { MT disassembly }\end{array}$ & $\begin{array}{l}\text { naïve pluripotent: } 8+\mathrm{h} \\
\text { pluripotency exit: } \sim 4 \mathrm{~h}\end{array}$ & $?$ & 69 \\
\hline & $\begin{array}{l}\text { Drosophila epithelium } \\
\text { (notum) }\end{array}$ & $\begin{array}{l}\text { Anaphase onset to } \\
\text { MT disassembly }\end{array}$ & $\begin{array}{l}\text { MT disassembly at } 42 \mathrm{~min} \text {. } \\
\text { Diffusion up to } 5 \mathrm{~h}\end{array}$ & No abscission on $2^{\text {nd }}$ flank & 58 \\
\hline \multirow[t]{3}{*}{$\begin{array}{l}\text { Tissues } \\
\text { in vivo }\end{array}$} & Zebrafish Blastula & MB formation to MBR release & $\begin{array}{l}\text { Cell cycle } 7: 40 \mathrm{~min} \\
\text { Cell cycle 12: } \sim 20 \mathrm{~min}\end{array}$ & $?$ & 72 \\
\hline & $\begin{array}{l}\text { C. elegans first cell } \\
\text { division }\end{array}$ & $\begin{array}{l}\text { Furrow ingression to } \\
\text { MT disassembly }\end{array}$ & $\sim 6.5 \mathrm{~min}$ & $?$ & 81 \\
\hline & $\begin{array}{l}\text { mouse NSCs in } \\
\text { embryonic cortex } \\
\text { explant }\end{array}$ & $\begin{array}{l}\text { MB formation to } \\
\text { MT disassembly }\end{array}$ & $\begin{array}{l}\text { E11.5: } 57 \mathrm{~min} \\
\text { E13.5: } 47 \mathrm{~min}\end{array}$ & $\begin{array}{l}\text { Medians: } \\
\text { E11.5: } 30 \mathrm{~min} \\
\text { E13.5: } 15 \mathrm{~min}\end{array}$ & 65 \\
\hline
\end{tabular}

cells and neurons [29•]. Overall, the Cep55 knockout mouse has a small brain due primarily to increased NSC apoptosis, but also premature neurogenesis [29•]. Interestingly, the apoptosis is dependent on $\mathrm{p} 53$, but the premature neurogenesis is not [29•]. This is different than in cell line studies, where p53mediated cell cycle arrest follows cytokinesis failure (cleavage furrow regression) [76]. It appears that NSCs have a non-p53 pathway that promotes NSC daughter cell differentiation into neurons when abscission is perturbed [46]. It is unknown if this pathway is activated by abscission duration or by proteins in the midbody, directly or indirectly.

\section{Midbody Remnants: Trash Can or Treasure?}

Once abscission has occurred, the post-abscission midbody is referred to as the midbody remnant (MBR). The completion of abscission on one or both flanks of the midbody determines whether the MBR is directly inherited by one daughter cell, or released into extracellular space. If it is released, the MBR can be internalized by one of the daughter cells or neighbor cells $[11,14]$. Proteomics and lipidomics approaches have revealed that the MBR contains over 400 proteins and is enriched for certain lipids $[3 \bullet \bullet, 4,77,78]$. This raises the question: is the cell wasting all this material, or does the MBR serve a role, as either a trash receptacle or a treasure chest (Figure 3D)?

\section{Abscission: Bilateral or Unilateral?}

Recruitment and assembly of the abscission machinery within the midbody is temporally and spatially regulated [10]; however, regulation of abscission on one flank (unilateral) or both flanks of the MB (bilateral) across development and model systems is not well understood. It is plausible that bilateral or unilateral abscission could influence the symmetry of divisions and the resulting daughter cell fate. In MDCK cells cultured as a 2-D monolayer polarized epithelium, some MBRs were observed to be attached to cells by a very thin plasma membrane tether, as seen by scanning electron microscopy [79]. It is not clear whether this tether is long-lasting, or represents an intermediate stage of abscission when only one flank has been cut. In a different scanning electron microscopy study using HeLa cells, this membrane tether was not observed [11]. In other reports in HeLa, dissociated MDCK, and C. elegans embryonic cells, the majority of cells completed bilateral abscission [10, 11, 14, 36, 80-82].

Interestingly, in NSCs, we find that bilateral abscission is observable in most divisions regardless of developmental age (E11 and E13) or duration of abscission [65••]. It is possible that unilateral abscission occurs at a later stage of brain development, but we were unable to assay this due to tissue thickness. The presence of thin membrane tethers to MBRs, as was seen in MDCK monolayers, has not been ruled out in NSCs. 
Midbody Remnants May Influence Daughter Cell Fate

As we discussed previously, MBRs from other cell types have the ability to influence polarity from both within the cell or from the cell surface. There is also evidence for MBR influence on cell fate. In different cell types examined so far, MBRs are sometimes associated with differentiation and sometimes with proliferation. In the Drosophila germline stem cells, MBR inheritance is stereotyped, and blocking abscission results in mixed daughter cell fates $[70,83]$. In the $C$. elegans early embryo, the MBR formed by the first cell division is retained in the posterior daughter, ablating it disrupts embryogenesis, and MBR inheritance is stereotyped in the lineage [15]. Later in C. elegans development, in L1 larvae, the Q neuroblast has stereotyped asymmetric divisions that result in three neurons and two apoptotic cells. All of the MBRs from these divisions are released extracellularly and engulfed by a specific neighboring cell that is also responsible for clearing apoptotic cells [14]. These data are consistent with the idea that MBR disposal is regulated developmentally, and that the MBR is shed or degraded by differentiating daughter cells.

Once the midbody is released extracellularly, is it engulfed because it is treasure, or a trash can needing to be degraded? Multiple groups have shown that cancer cells release MBRs and then proceed to engulf and accumulate MBRs at a higher rate compared to stem cells or other cell lines [11, 12, 16, 84]. Interestingly, the accumulation of engulfed MBRs in cancer cells lines is enabled by MBRs' ability to avoid the lysosome, perhaps by the membrane-bounded MBR coating with actin patches [12]. Limited work has been done on the downstream effect of engulfing midbodies. In HeLa, cells containing MBRs increased transcriptional activity that promotes cell proliferation compared to HeLa cells without MBRs [12]. This is evidence that MBRs could directly influence the ability of a cell to proliferate. MBRs could also be a trash can for stem cells to eliminate damaged proteins or to remove differentiation factors, and therefore would need to be engulfed and degraded. More work on downstream effects of engulfing midbodies across cell types is needed.

Do MBRs influence cell fate in NSC divisions in developing brain? The answer is not known, but there are some suggestive correlations. As mentioned previously, NSC MBRs are deposited at the apical membrane, where many fatesignaling events occur. We showed that MBRs were more abundant on the apical membranes of early brains, when NSC divisions are more symmetric proliferative, compared to later ages, when NSC divisions are more asymmetric and neurogenic [65••]. Additionally, in E11 NSC divisions in culture, MBRs are more likely to be associated with proliferative divisions than neurogenic divisions. These differences suggest developmental regulation of MBR release (bilateral vs unilateral), adhesion to membrane, or engulfment/degradation pathways. It is unknown whether NSCs internalize MBRs. To date, the only mouse mutant that affects the abundance of MBRs in the developing brain is the Cep55 knockout. Despite some NSCs failing at cytokinesis and becoming binucleate, there are increased MBRs on the apical membrane, regardless of developmental stage [29•]. This could be a manifestation of the delayed abscission found in the Cep 55 mutant NSCs. Alternatively, it could be due to defective MBR disposal or degradation.

\section{Midbody Remnants May Influence Ciliogenesis}

NSCs in the cortical neuroepithelium each have a primary cilium on their apical membrane that serves as an antenna to receive signals from the cerebrospinal fluid, and best known to mediate sonic hedgehog (Shh) signaling [85]. Each cell disassembles its cilium as it prepares for mitosis, and regrows it after mitosis, during the same time window as abscission occurs. This raises the question, do midbodies or MBRs influence cilia growth? There is evidence from MDCK cells cultured as a monolayer polarized epithelium that MBRs enhance ciliogenesis. Following abscission of MDCK cells, MBRs move along the outside of the apical membrane toward the centrosome at the cell apex [13]. It was proposed that the MBR delivers a special membrane patch to the centrosome, and once this interaction happens, the cell begins to grow its cilium [86, 87]. Physically or genetically removing MBRs from the surface reduced the percentage of the MDCK cells developing a primary cilium $[13,79]$. These data suggest that, at least in this cell type, the MBR promotes ciliogenesis, perhaps by direct contact. It remains to be seen whether this is also true in other epithelia.

The MBR has been implicated in cell fate and establishment of polarity. While it is clear that there are cell-type differences, the MBR is emerging as an important signaling component. The MBR could serve as a "trash can" receptacle to sequester differentiation-promoting factors, and release of the MBR could be essential to keep stemness and prevent differentiation. In addition or alternatively, the MBR may be a "treasure chest" that promotes proliferation or ciliogenesis (Figure 3D). These roles or MBR contents may be adapted in different cell types or at different developmental stages. More work is needed to understand the importance of the MBR during cortical development and in other stem cells in different developmental contexts.

\section{Conclusion}

Stem cells have special requirements for cell division and cytokinesis, to maintain stemness as they proliferate and then to produce various types of daughter cells during development. Neural stem cells of the embryonic mammalian brain are highly polarized with tiny apical membranes and divide 
both symmetrically and asymmetrically to produce billions of daughter cells in a short time. This may be why mutations in abscission genes affect brain development more severely than other tissues. These mouse mutant studies, along with evidence from simpler systems, suggest that regulation of midbody positioning in relation to apical junctions, abscission duration, and MBRs contribute to brain development. The mechanisms of how these aspects of abscission are controlled and how they may affect the balance of proliferation versus differentiation are only beginning to be elucidated. Much remains to be learned about how NSCs and other stem cells regulate these different aspects of abscission in order to build polarized tissue structure and give rise to the right daughter cells at the right times.

Funding The authors are supported by grants from the NINDS (R01NS116054) and the NICHD (R01HD102492) to N.D.D.

\section{Compliance with Ethical Standards}

Conflict of Interest Katrina C. McNeely and Noelle D. Dwyer declare that they have no conflicts of interest.

Human and Animal Rights and Informed Consent All reported studies/ experiments with human or animal subjects performed by the authors have been previously published and complied with all applicable ethical standards (including the Helsinki declaration and its amendments, institutional/national research committee standards, and international/national/institutional guidelines).

Open Access This article is licensed under a Creative Commons Attribution 4.0 International License, which permits use, sharing, adaptation, distribution and reproduction in any medium or format, as long as you give appropriate credit to the original author(s) and the source, provide a link to the Creative Commons licence, and indicate if changes were made. The images or other third party material in this article are included in the article's Creative Commons licence, unless indicated otherwise in a credit line to the material. If material is not included in the article's Creative Commons licence and your intended use is not permitted by statutory regulation or exceeds the permitted use, you will need to obtain permission directly from the copyright holder. To view a copy of this licence, visit http://creativecommons.org/licenses/by/4.0/.

\section{References}

Papers of particular interest, published recently, have been highlighted as:

- Of importance

•• Of major importance

1. Lin Y, Yang J, Shen Z, Ma J, Simons BD, Shi SH. Behavior and lineage progression of neural progenitors in the mammalian cortex. Curr Opin Neurobiol. 2021;66:144-57. https://doi.org/10.1016/j. conb.2020.10.017.
2. Gershony O, Pe'er T, Noach-Hirsh M, Elia N, Tzur A. Cytokinetic abscission is an acute G1 event. Cell Cycle. 2014;13(21):3436-41. https://doi.org/10.4161/15384101.2014.956486.

3.• Addi C, Presle A, Fremont S, Cuvelier F, Rocancourt M, Milin F, et al. The Flemmingsome reveals an ESCRT-to-membrane coupling via ALIX/syntenin/syndecan-4 required for completion of cytokinesis. Nat Commun. 2020;11(1):1941. https://doi.org/10. 1038/s41467-020-15205-z Developed an efficient method to purify intact post-abscission midbody remnants (Flemming bodies) from HeLa cells to obtain a proteome and identify 489 enriched proteins.

4. Skop AR, Liu H, Yates J 3rd, Meyer BJ, Heald R. Dissection of the mammalian midbody proteome reveals conserved cytokinesis mechanisms. Science. 2004;305(5680):61-6. https://doi.org/10. 1126/science.1097931.

5. Green RA, Paluch E, Oegema K. Cytokinesis in animal cells. Annu Rev Cell Dev Biol. 2012;28:29-58. https://doi.org/10.1146/ annurev-cellbio-101011-155718.

6. $\mathrm{Hu} \mathrm{CK}$, Coughlin M, Mitchison TJ. Midbody assembly and its regulation during cytokinesis. Mol Biol Cell. 2012;23(6):1024 34. https://doi.org/10.1091/mbc.E11-08-0721.

7. Addi C, Bai J, Echard A. Actin, microtubule, septin and ESCRT filament remodeling during late steps of cytokinesis. Curr Opin Cell Biol. 2018;50:27-34. https://doi.org/10.1016/j.ceb.2018.01.007.

8. Stoten CL, Carlton JG. ESCRT-dependent control of membrane remodelling during cell division. Semin Cell Dev Biol. 2018;74: 50-65. https://doi.org/10.1016/j.semcdb.2017.08.035.

9. Steigemann P, Wurzenberger C, Schmitz MH, Held M, Guizetti J, Maar S, et al. Aurora B-mediated abscission checkpoint protects against tetraploidization. Cell. 2009;136(3):473-84. https://doi.org/ 10.1016/j.cell.2008.12.020

10. Guizetti J, Schermelleh L, Mantler J, Maar S, Poser I, Leonhardt H, et al. Cortical constriction during abscission involves helices of ESCRT-III-dependent filaments. Science. 2011;331(6024):161620. https://doi.org/10.1126/science.1201847.

11. Crowell EF, Gaffuri AL, Gayraud-Morel B, Tajbakhsh S, Echard A. Engulfment of the midbody remnant after cytokinesis in mammalian cells. J Cell Sci. 2014;127(Pt 17):3840-51. https://doi.org/ $10.1242 /$ jcs. 154732 .

12. Peterman E, Gibieza P, Schafer J, Skeberdis VA, Kaupinis A, Valius M, et al. The post-abscission midbody is an intracellular signaling organelle that regulates cell proliferation. Nat Commun. 2019;10(1):3181. https://doi.org/10.1038/s41467-019-10871-0.

13. Bernabe-Rubio M, Andres G, Casares-Arias J, Fernandez-Barrera J, Rangel L, Reglero-Real N, et al. Novel role for the midbody in primary ciliogenesis by polarized epithelial cells. J Cell Biol. 2016;214(3):259-73. https://doi.org/10.1083/jcb.201601020.

14. Chai Y, Tian D, Yang Y, Feng G, Cheng Z, Li W, et al. Apoptotic regulators promote cytokinetic midbody degradation in $\mathrm{C}$. elegans. J Cell Biol. 2012;199(7):1047-55. https://doi.org/10.1083/jcb. 201209050.

15. Singh D, Pohl C. Coupling of rotational cortical flow, asymmetric midbody positioning, and spindle rotation mediates dorsoventral axis formation in C. elegans. Dev Cell. 2014;28(3):253-67. https://doi.org/10.1016/j.devcel.2014.01.002.

16. Ettinger AW, Wilsch-Brauninger M, Marzesco AM, Bickle M, Lohmann A, Maliga Z, et al. Proliferating versus differentiating stem and cancer cells exhibit distinct midbody-release behaviour. Nat Commun. 2011;2:503. https://doi.org/10.1038/ncomms1511.

17. Kuo TC, Chen CT, Baron D, Onder TT, Loewer S, Almeida S, et al. Midbody accumulation through evasion of autophagy contributes to cellular reprogramming and tumorigenicity. Nat Cell Biol. 2011;13(10):1214-23. https://doi.org/10.1038/ncb2332.

18. Bondeson ML, Ericson K, Gudmundsson S, Ameur A, Ponten F, Wesstrom $\mathrm{J}$, et al. A nonsense mutation in CEP55 defines a new locus for a Meckel-like syndrome, an autosomal recessive lethal 
fetal ciliopathy. Clin Genet. 2017;92(5):510-6. https://doi.org/10. 1111/cge.13012.

19. Di Cunto F, Imarisio S, Hirsch E, Broccoli V, Bulfone A, Migheli $A$, et al. Defective neurogenesis in citron kinase knockout mice by altered cytokinesis and massive apoptosis. Neuron. 2000;28(1): 115-27. https://doi.org/10.1016/s0896-6273(00)00090-8.

20. Frosk P, Arts HH, Philippe J, Gunn CS, Brown EL, Chodirker B, et al. Canadian Rare Diseases M, Mechanisms N, Hegele R, et al. A truncating mutation in CEP55 is the likely cause of MARCH, a novel syndrome affecting neuronal mitosis. J Med Genet. 2017;54(7):490-501. https://doi.org/10.1136/jmedgenet-2016104296.

21. Janisch KM, Vock VM, Fleming MS, Shrestha A, Grimsley-Myers CM, Rasoul BA, et al. The vertebrate-specific Kinesin-6, Kif20b, is required for normal cytokinesis of polarized cortical stem cells and cerebral cortex size. Development. 2013;140(23):4672-82. https:// doi.org/10.1242/dev.093286.

22. Li H, Bielas SL, Zaki MS, Ismail S, Farfara D, Um K, et al. Biallelic mutations in citron kinase link mitotic cytokinesis to human primary microcephaly. Am J Hum Genet. 2016;99(2):501-10. https://doi. org/10.1016/j.ajhg.2016.07.004.

23. Qiu R, Runxiang Q, Geng A, Liu J, Xu CW, Menon MB, et al. SEPT7 interacts with KIF20A and regulates the proliferative state of neural progenitor cells during cortical development. Cereb Cortex. 2019;30(5):3030-43. https://doi.org/10.1093/cercor/ bhz292.

24. Tedeschi A, Almagro J, Renshaw MJ, Messal HA, Behrens A, Petronczki M. Cep55 promotes cytokinesis of neural progenitors but is dispensable for most mammalian cell divisions. Nat Commun. 2020;11(1):1746. https://doi.org/10.1038/s41467-02015359-w Demonstrated that Cep55 knockout causes postnatal lethality and disrupts brain growth, but spares development of other tissues.

25. Fujikura K, Setsu T, Tanigaki K, Abe T, Kiyonari H, Terashima T, et al. Kif14 mutation causes severe brain malformation and hypomyelination. PLoS One. 2013;8(1):e53490. https://doi.org/ 10.1371/journal.pone.0053490.

26. Moawia A, Shaheen R, Rasool S, Waseem SS, Ewida N, Budde B, et al. Mutations of KIF14 cause primary microcephaly by impairing cytokinesis. Ann Neurol. 2017;82(4):562-77. https://doi.org/10. 1002/ana.25044.

27. Reilly ML, Stokman MF, Magry V, Jeanpierre C, Alves M, Paydar $\mathrm{M}$, et al. Loss-of-function mutations in KIF14 cause severe microcephaly and kidney development defects in humans and zebrafish. Hum Mol Genet. 2019;28(5):778-95. https://doi.org/10.1093/hmg/ ddy381.

28. Geng A, Qiu R, Murai K, Liu J, Wu X, Zhang H, et al. KIF20A/ MKLP2 regulates the division modes of neural progenitor cells during cortical development. Nat Commun. 2018;9(1):2707. https://doi.org/10.1038/s41467-018-05152-1.

29. L Little JN, KC MN, Michel N, Bott CJ, Lettieri KS, Hecht MR, et al. Loss of coiled-coil protein Cep55 impairs neural stem cell abscission and results in p53-dependent apoptosis in developing cortex. $\mathrm{J}$ Neurosci. 2021;41(15):3344-65. https://doi.org/10.1523/ JNEUROSCI.1955-20.2021 Demonstrated that Cep55 promotes the timely and successful completion of abscission in neural stem cells and proper brain growth. Defective abscission leads to cell cycle exit and apoptosis in the brain but not other cells.

30. Rawlins LE, Jones H, Wenger O, Aye M, Fasham J, Harlalka GV, et al. An Amish founder variant consolidates disruption of CEP55 as a cause of hydranencephaly and renal dysplasia. Eur J Hum Genet. 2019;27(4):657-62. https://doi.org/10.1038/s41431-0180306-0.

31. Barrie ES, Overwater E, van Haelst MM, Motazacker MM, Truxal $\mathrm{KV}$, Crist E, et al. Expanding the spectrum of CEP55-associated disease to viable phenotypes. Am J Med Genet A. 2020;182(5): 1201-8. https://doi.org/10.1002/ajmg.a.61512.

32. Makrythanasis P, Maroofian R, Stray-Pedersen A, Musaev D, Zaki MS, Mahmoud IG, et al. Biallelic variants in KIF14 cause intellectual disability with microcephaly. Eur J Hum Genet. 2018;26(3): 330-9. https://doi.org/10.1038/s41431-017-0088-9.

33. Harding BN, Moccia A, Drunat S, Soukarieh O, Tubeuf H, Chitty LS, et al. Mutations in citron kinase cause recessive microlissencephaly with multinucleated neurons. Am J Hum Genet. 2016;99(2):511-20. https://doi.org/10.1016/j.ajhg.2016.07. 003.

34. Shaheen R, Hashem A, Abdel-Salam GM, Al-Fadhli F, Ewida N, Alkuraya FS. Mutations in CIT, encoding citron rho-interacting serine/threonine kinase, cause severe primary microcephaly in humans. Hum Genet. 2016;135(10):1191-7. https://doi.org/10. 1007/s00439-016-1722-2.

35. Menon MB, Sawada A, Chaturvedi A, Mishra P, Schuster-Gossler K, Galla M, et al. Genetic deletion of SEPT7 reveals a cell typespecific role of septins in microtubule destabilization for the completion of cytokinesis. PLoS Genet. 2014;10(8):e1004558. https:// doi.org/10.1371/journal.pgen.1004558.

36. Janisch KM, McNeely KC, Dardick JM, Lim SH, Dwyer ND. Kinesin-6 KIF20B is required for efficient cytokinetic furrowing and timely abscission in human cells. Mol Biol Cell. 2018;29(2): 166-79. https://doi.org/10.1091/mbc.E17-08-0495.

37. Gruneberg U, Neef R, Honda R, Nigg EA, Barr FA. Relocation of Aurora $\mathrm{B}$ from centromeres to the central spindle at the metaphase to anaphase transition requires MKlp2. J Cell Biol. 2004;166(2): 167-72. https://doi.org/10.1083/jcb.200403084.

38. Fung SYS, Kitagawa M, Liao PJ, Wong J, Lee SH. Opposing activities of Aurora B kinase and B56-PP2A phosphatase on MKlp2 determine abscission timing. Curr Biol. 2017;27(1):7886. https://doi.org/10.1016/j.cub.2016.10.042.

39. Menon MB, Gaestel M. Sep(t)arate or not - how some cells take septin-independent routes through cytokinesis. J Cell Sci. 2015;128(10):1877-86. https://doi.org/10.1242/jcs.164830.

40. Estey MP, Di Ciano-Oliveira C, Froese CD, Bejide MT, Trimble WS. Distinct roles of septins in cytokinesis: SEPT9 mediates midbody abscission. J Cell Biol. 2010;191(4):741-9. https://doi. org/10.1083/jcb.201006031.

41. Gruneberg U, Neef R, Li X, Chan EH, Chalamalasetty RB, Nigg EA, et al. KIF14 and citron kinase act together to promote efficient cytokinesis. J Cell Biol. 2006;172(3):363-72. https://doi.org/10. 1083/jcb.200511061.

42. D'Avino PP. Citron kinase - renaissance of a neglected mitotic kinase. J Cell Sci. 2017;130(10):1701-8. https://doi.org/10.1242/ jcs.200253.

43. Vietri M, Radulovic M, Stenmark H. The many functions of ESCRTs. Nat Rev Mol Cell Biol. 2020;21(1):25-42. https://doi. org/10.1038/s41580-019-0177-4.

44. Pohl C, Jentsch S. Final stages of cytokinesis and midbody ring formation are controlled by BRUCE. Cell. 2008;132(5):832-45. https://doi.org/10.1016/j.cell.2008.01.012.

45. Gromley A, Jurczyk A, Sillibourne J, Halilovic E, Mogensen M, Groisman I, et al. A novel human protein of the maternal centriole is required for the final stages of cytokinesis and entry into $\mathrm{S}$ phase. $\mathrm{J}$ Cell Biol. 2003;161(3):535-45. https://doi.org/10.1083/jcb. 200301105.

46. Little JN, Dwyer ND. p53 deletion rescues lethal microcephaly in a mouse model with neural stem cell abscission defects. Hum Mol Genet. 2019;28(3):434-47. https://doi.org/10.1093/hmg/ddy350.

47. Bianchi FT, Tocco C, Pallavicini G, Liu Y, Verni F, Merigliano C, et al. Citron kinase deficiency leads to chromosomal instability and TP53-sensitive microcephaly. Cell Rep. 2017;18(7):1674-86. https://doi.org/10.1016/j.celrep.2017.01.054. 
48. Bowen ME, McClendon J, Long HK, Sorayya A, Van Nostrand JL, Wysocka J, et al. The spatiotemporal pattern and intensity of p53 activation dictates phenotypic diversity in p53-driven developmental syndromes. Dev Cell. 2019;50(2):212-28 e6. https://doi.org/10. 1016/j.devcel.2019.05.015.

49. Bonnefont J, Vanderhaeghen P. Neuronal fate acquisition and specification: time for a change. Curr Opin Neurobiol. 2021;66:195204. https://doi.org/10.1016/j.conb.2020.12.006.

50. Slaughter BD, Smith SE, Li R. Symmetry breaking in the life cycle of the budding yeast. Cold Spring Harb Perspect Biol. 2009;1(3): a003384. https://doi.org/10.1101/cshperspect.a003384.

51. Pollarolo G, Schulz JG, Munck S, Dotti CG. Cytokinesis remnants define first neuronal asymmetry in vivo. Nat Neurosci. 2011;14(12):1525-33. https://doi.org/10.1038/nn.2976.

52. Bai X, Melesse M, Sorensen Turpin CG, Sloan DE, Chen CY, Wang WC, et al. Aurora B functions at the apical surface after specialized cytokinesis during morphogenesis in C. elegans. Development. 2020;147(1). https://doi.org/10.1242/dev.181099.

53. Jaffe AB, Kaji N, Durgan J, Hall A. Cdc42 controls spindle orientation to position the apical surface during epithelial morphogenesis. J Cell Biol. 2008;183(4):625-33. https://doi.org/10.1083/jcb. 200807121.

54. Li D, Mangan A, Cicchini L, Margolis B, Prekeris R. FIP5 phosphorylation during mitosis regulates apical trafficking and lumenogenesis. EMBO Rep. 2014;15(4):428-37. https://doi.org/ 10.1002/embr.201338128.

55. Lujan P, Varsano G, Rubio T, Hennrich ML, Sachsenheimer T, Galvez-Santisteban M, et al. PRL-3 disrupts epithelial architecture by altering the post-mitotic midbody position. J Cell Sci. 2016;129(21):4130-42. https://doi.org/10.1242/jcs.190215.

56. Rathbun LI, Colicino EG, Manikas J, O'Connell J, Krishnan N, Reilly NS, et al. Cytokinetic bridge triggers de novo lumen formation in vivo. Nat Commun. 2020;11(1):1269. https://doi.org/10. 1038/s41467-020-15002-8 Demonstrated that midbodies are positioned to direct polarized delivery of cargo to establish the lumen of a polarized epithelium in vivo.

57. Herszterg S, Pinheiro D, Bellaiche Y. A multicellular view of cytokinesis in epithelial tissue. Trends Cell Biol. 2014;24(5):285-93. https://doi.org/10.1016/j.tcb.2013.11.009.

58. Daniel E, Daude M, Kolotuev I, Charish K, Auld V, Le Borgne R. Coordination of septate junctions assembly and completion of cytokinesis in proliferative epithelial tissues. Curr Biol. 2018;28(9): 1380-91 e4. https://doi.org/10.1016/j.cub.2018.03.034.

59. Higashi T, Arnold TR, Stephenson RE, Dinshaw KM, Miller AL. Maintenance of the epithelial barrier and remodeling of cell-cell junctions during cytokinesis. Curr Biol. 2016;26(14):1829-42. https://doi.org/10.1016/j.cub.2016.05.036.

60. Trylinski M, Mazouni K, Schweisguth F. Intra-lineage fate decisions involve activation of notch receptors basal to the midbody in drosophila sensory organ precursor cells. Curr Biol. 2017;27(15): 2239-47 e3. https://doi.org/10.1016/j.cub.2017.06.030.

61. Morais-de-Sa E, Sunkel C. Adherens junctions determine the apical position of the midbody during follicular epithelial cell division. EMBO Rep. 2013;14(8):696-703. https://doi.org/10.1038/embor. 2013.85.

62. Dubreuil V, Marzesco AM, Corbeil D, Huttner WB, WilschBrauninger M. Midbody and primary cilium of neural progenitors release extracellular membrane particles enriched in the stem cell marker prominin-1. J Cell Biol. 2007;176(4):483-95. https://doi. org/10.1083/jcb.200608137.

63. Kim S, Lehtinen MK, Sessa A, Zappaterra MW, Cho SH, Gonzalez $\mathrm{D}$, et al. The apical complex couples cell fate and cell survival to cerebral cortical development. Neuron. 2010;66(1):69-84. https:// doi.org/10.1016/j.neuron.2010.03.019.
64. Paridaen JT, Huttner WB. Neurogenesis during development of the vertebrate central nervous system. EMBO Rep. 2014;15(4):35164. https://doi.org/10.1002/embr.201438447.

65.• McNeely KC, Dwyer ND. Cytokinesis and postabscission midbody remnants are regulated during mammalian brain development. Proc Natl Acad Sci U S A. 2020;117(17):9584-93. https:// doi.org/10.1073/pnas.1919658117 Quantitatively analyzed abscission in NSCs of intact brain explants at different ages, and showed developmental regulation of midbody remnant persistence at the apical membrane. Demonstrated that loss of Kif20b causes accelerated abscission and increased cell cycle exit.

66. Dalton S. Linking the cell cycle to cell fate decisions. Trends Cell Biol. 2015;25(10):592-600. https://doi.org/10.1016/j.tcb.2015.07. 007.

67. Iwata R, Casimir P, Vanderhaeghen P. Mitochondrial dynamics in postmitotic cells regulate neurogenesis. Science. 2020;369(6505): 858-62. https://doi.org/10.1126/science.aba9760.

68. Nahse V, Christ L, Stenmark H, Campsteijn C. The abscission checkpoint: making it to the final cut. Trends Cell Biol. 2017;27(1):1-11. https://doi.org/10.1016/j.tcb.2016.10.001.

69.• Chaigne A, Labouesse C, White IJ, Agnew M, Hannezo E, Chalut $\mathrm{KJ}$, et al. Abscission couples cell division to embryonic stem cell fate. Dev Cell. 2020;55(2):195-208 e5. https://doi.org/10.1016/j. devcel.2020.09.001 Showed abscission accelerates as cultured mouse embryonic stem cells exit naïve pluripotency.

70. Lenhart KF, DiNardo S. Somatic cell encystment promotes abscission in germline stem cells following a regulated block in cytokinesis. Dev Cell. 2015;34(2):192-205. https://doi.org/10.1016/j. devcel.2015.05.003.

71. Zenker J, White MD, Templin RM, Parton RG, Thorn-Seshold O, Bissiere S, et al. A microtubule-organizing center directing intracellular transport in the early mouse embryo. Science. 2017;357(6354):925-8. https://doi.org/10.1126/science.aam9335.

72. Adar-Levor S, Nachmias D, Gal-Oz ST, Jahn YM, Peyrieras N, Zaritsky A, et al. Cytokinetic abscission is part of the midblastula transition in early zebrafish embryogenesis. Proc Natl Acad Sci U S A. 2021;118(15). https://doi.org/10.1073/pnas.2021210118.

73. Lee HH, Elia N, Ghirlando R, Lippincott-Schwartz J, Hurley JH. Midbody targeting of the ESCRT machinery by a noncanonical coiled coil in CEP55. Science. 2008;322(5901):576-80. https:// doi.org/10.1126/science.1162042.

74. Morita E, Sandrin V, Chung HY, Morham SG, Gygi SP, Rodesch $\mathrm{CK}$, et al. Human ESCRT and ALIX proteins interact with proteins of the midbody and function in cytokinesis. EMBO J. 2007;26(19): 4215-27. https://doi.org/10.1038/sj.emboj.7601850.

75. Zhao WM, Seki A, Fang G. Cep55, a microtubule-bundling protein, associates with centralspindlin to control the midbody integrity and cell abscission during cytokinesis. Mol Biol Cell. 2006;17(9): 3881-96. https://doi.org/10.1091/mbc.e06-01-0015.

76. McKinley KL, Cheeseman IM. Large-scale analysis of CRISPR/ Cas9 cell-cycle knockouts reveals the diversity of p53-dependent responses to cell-cycle defects. Dev Cell. 2017;40(4):405-20 e2. https://doi.org/10.1016/j.devcel.2017.01.012.

77. Arai Y, Sampaio JL, Wilsch-Brauninger M, Ettinger AW, Haffner C, Huttner WB. Lipidome of midbody released from neural stem and progenitor cells during mammalian cortical neurogenesis. Front Cell Neurosci. 2015;9:325. https://doi.org/10.3389/fncel.2015. 00325 .

78. Atilla-Gokcumen GE, Muro E, Relat-Goberna J, Sasse S, Bedigian A, Coughlin ML, et al. Dividing cells regulate their lipid composition and localization. Cell. 2014;156(3):428-39. https://doi.org/10. 1016/j.cell.2013.12.015.

79. Casares-Arias J, Gonzalez MU, San Paulo A, Ventimiglia LN, Sadler JBA, Miguez DG, et al. Midbody remnant inheritance is 
regulated by the ESCRT subunit CHMP4C. iScience. 2020;23(6): 101244. https://doi.org/10.1016/j.isci.2020.101244.

80. Gershony O, Sherman S, Adar S, Segal I, Nachmias D, Goliand I, et al. Measuring abscission spatiotemporal dynamics using quantitative high-resolution microscopy. Methods Cell Biol. 2017;137: 205-24. https://doi.org/10.1016/bs.mcb.2016.03.032.

81. Konig J, Frankel EB, Audhya A, Muller-Reichert T. Membrane remodeling during embryonic abscission in Caenorhabditis elegans. J Cell Biol. 2017;216(5):1277-86. https://doi.org/10. 1083/jcb.201607030.

82. Lafaurie-Janvore J, Maiuri P, Wang I, Pinot M, Manneville JB, Betz T, et al. ESCRT-III assembly and cytokinetic abscission are induced by tension release in the intercellular bridge. Science. 2013;339(6127):1625-9. https://doi.org/10.1126/science.1233866.

83. Salzmann V, Chen C, Chiang CY, Tiyaboonchai A, Mayer M, Yamashita YM. Centrosome-dependent asymmetric inheritance of the midbody ring in Drosophila germline stem cell division. Mol Biol Cell. 2014;25(2):267-75. https://doi.org/10.1091/mbc.E1309-0541.

84. Dionne LK, Peterman E, Schiel J, Gibieza P, Skeberdis VA, Jimeno A, et al. FYCO1 regulates accumulation of post-mitotic midbodies by mediating LC3-dependent midbody degradation. J Cell Sci. 2017;130(23):4051-62. https://doi.org/10.1242/jcs.208983.

85. Park SM, Jang HJ, Lee JH. Roles of primary cilia in the developing brain. Front Cell Neurosci. 2019;13:218. https://doi.org/10.3389/ fncel.2019.00218.

86. Bernabé-Rubio M, Bosch-Fortea M, García E, Bernardino de la Serna J, Alonso MA. Adaptive lipid immiscibility and membrane remodeling are active functional determinants of primary ciliogenesis. Small Methods. 2020;5(2):2000711. https://doi.org/ 10.1002/smtd.202000711.

87. Labat-de-Hoz L, Rubio-Ramos A, Casares-Arias J, Bernabe-Rubio M, Correas I, Alonso MA. A model for primary cilium biogenesis by polarized epithelial cells: role of the midbody remnant and associated specialized membranes. Front Cell Dev Biol. 2020;8: 622918. https://doi.org/10.3389/fcell.2020.622918.

Publisher's Note Springer Nature remains neutral with regard to jurisdictional claims in published maps and institutional affiliations. 